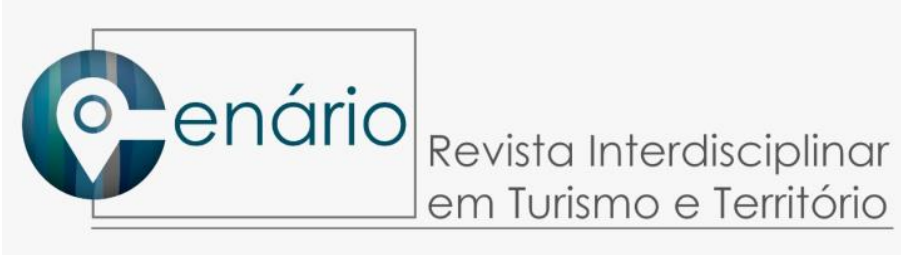

\title{
Perspectivas
}

\section{O FUTURO DO TURISMO}

Mozart Fazito ${ }^{1}$

Este artigo é o produto de um convite feito a mim pela editora da Revista Cenário, Profa. Kerlei Sonaglio, para refletir sobre o futuro do turismo no contexto da pandemia de COVID-19. Por ser uma reflexão, este texto exige o meu posicionamento pessoal, mas faço-o investido da minha condição de professor e pesquisador social, especialista em planejamento do turismo e geografia do desenvolvimento. Muitos autores escreveram, falaram, escreverão e falarão, ainda nas próximas semanas, sobre quando o fluxo turístico irá voltar ao normal, as taxas de ocupação dos hotéis regressarão ao que eram antes da pandemia, sobre arrecadação municipal e a participação do turismo no PIB. Não me interessa falar disso nesse momento. Isso interessa à indústria que apoia o turismo, empresários do ramo de acomodação, alimentação e transportes. Não interessa ao mundo que quero imaginar aqui. Quero refletir sobre o tempo e sobre a ideia de 'futuro', e de construção do que seria uma sociedade melhor do que a que temos hoje. Tento me comunicar de forma mais clara, evitando os termos que afastam os leitores de fora da academia, e apresento leituras facilitadas, entrevistas e videoaulas para servirem de referência. Essas referências são apresentadas em notas de rodapé, para fazer fluir a leitura.

\section{PLANEJAMENTO, POESIA E O GOVERNO DO FUTURO DAS SOCIEDADES}

As sociedades pré-capitalistas não tinham governo nenhum sobre o futuro. Os acontecimentos se davam de forma natural e seus resultados, bons ou ruins, eram creditados a algum mito, algum deus agradecido ou enfurecido. O capitalismo emerge em um contexto de efervescência cultural e científica ${ }^{2}$. A capacidade de reconhecer padrões, descrever e medir as relações de causalidade que explicam os acontecimentos deram base à ciência aplicada e à produção do conhecimento técnico da forma como fazemos ainda hoje. A inteligência humana passou a acreditar conseguir dominar a natureza e governar o tempo futuro, ou pelo menos parte dele e dela. Para tanto, uma pressuposição da ciência é separar razão e emoção, de forma que

Este artigo é fruto de um projeto de pesquisa financiado pela Academia Britânica, no edital Newton Advanced Fellowships, e conta com período de permanência no Crime and Security Research Institute (Cardiff University), financiado pelo Programa de Internacionalização da CAPES (Coordenação de Aperfeiçoamento de Pessoal de Nível Superior).

${ }^{1}$ Prof. Adjunto do Departamento de Turismo da UFRN, pesquisador visitante do Crime and Security Research Institute, Cardiff University, pesquisador do Instituto Observatório da Violência (OBVIO) e colaborador do Comitê Científico de Combate ao COVID-19 junto ao Consórcio Nordeste.

2 Para uma boa descrição desse momento no contexto da origem dos estudos de desenvolvimento, e da tradição filosófica denominada 'positivismo', recomendo a leitura de Cowen e Shenton (2005).

CENÁRIO|ISSN 2318-8561|Brasília|V.8, n. 14|6 - 16|Jun. 2020| DOI: $10.26512 /$ revistacenario.v8i14.31957 


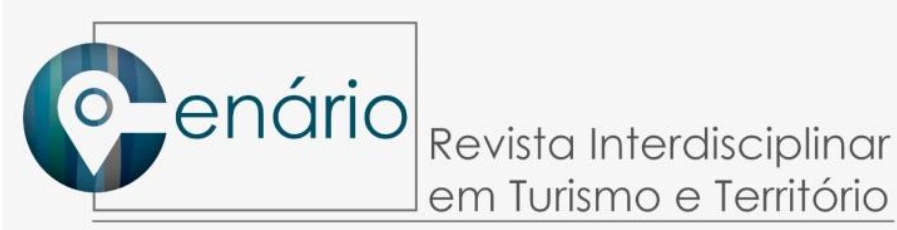

a análise dos fenômenos naturais e sociais sejam de responsabilidade da razão, e as emoções, paixões e outras subjetividades sejam postas de fora da análise.

Mas 'tempo' é um tema muito árido, posto que não podemos fazer a observação 'de fora' do objeto. Estamos imersos no tempo, assim não conseguimos nos 'livrar' das emoções, das paixões e outras subjetividades inerentes à nossa existência. Entretanto, quando o observador mais cuidadoso não suprimiu seus sentimentos, a filosofia do tempo nos trouxe reflexões profundas, deliciosas e inspiradoras ${ }^{3}$. Deixo-me levar, assim, pela forma como a arte me toca e influencia meu pensamento. Recordo-me de um gênio brasileiro levado pela COVID19, o 'ourives do palavreado', como descreveu Dorival Caymmi, Aldir Blanc. Assim que morreu, fui ouvir emocionado 'Resposta ao Tempo' ${ }^{4}$, em que ele narra um bate-papo que teve com 0 tempo, e que me inspirou a escrever este texto. Se o diálogo começa com o tempo zombando dele por não conseguir conter as paixões, a música termina com o tempo se roendo de inveja dele:

Respondo que ele aprisiona, eu liberto

Que ele adormece as paixões, eu desperto

E o tempo se rói com inveja de mim

Me vigia querendo aprender

Como eu morro de amor pra tentar reviver

Aldir termina por qualificar o tempo como uma criança imatura, incapaz de esquecê-lo. Essa pequena viagem ao mundo da arte me ajuda a justificar a minha imersão no mundo dos afetos, das paixões, para falar do tempo e de como a busca por suprimir as subjetividades nas ciências sociais e humanas leva ao mais nefasto dos futuros.

Nas ciências sociais, a ferramenta mais importante para definir, construir e governar o tempo das sociedades ganhou o nome de planejamento. Desde então, proliferaram definições de planejamento, mas o elemento comum a todas elas é a preocupação que o ato de planejar tem com o futuro. O processo básico de planejamento envolve a descrição da situação atual do objeto a ser planejado (diagnóstico), que dá base à construção de uma situação futura ideal ou desejável (prognóstico), a elaboração de um passo-a-passo para se sair da situação atual e atingir esse futuro desejável (plano de ações), a implementação e a avaliação desse plano. Em suas versões mais elaboradas, o processo de planejamento pode ser adaptativo, ou seja, ter alguma flexibilidade para se antever cenários mais otimistas ou pessimistas, ou estratégico, o que envolve a análise de elementos externos ao objeto, o chamado macroambiente, para definir esses diferentes cenários e tentar antever possíveis ameaças ou oportunidades para se atingir um futuro desejado no longo prazo, da melhor forma possível. Os planejadores lançam mão de complexas ferramentas estatísticas, de modelagem, análises qualitativas fortemente amparadas na literatura científica, tudo para que a tal situação futura desejada seja atingida. Ou seja, partese do que existe hoje (diagnóstico) para se depreender situações futuras desejáveis e, mais importante de tudo, viáveis! Viabilidade diz respeito à ponderação entre uma situação ideal e os

\footnotetext{
${ }^{3}$ Não há razão nenhuma para eu apresentar aqui ideias sobre as quais se debruçaram nossos antepassados mais brilhantes. Para uma viagem breve, mas alucinante, sugiro aos leitores assistirem o vídeo do professor Clóvis de Barros Filho https://www.youtube.com/watch?v=1Gd1v3W1 CE\&t=2432s, acesso em 10 de maio de 2020.

${ }^{4}$ A melhor versão, com o próprio Aldir Blanc cantando, se encontra aqui https://www.youtube.com/watch?v=Wqn07VvU3s0\&list=OLAK5uy mIPVZ3HkPCBh8ZeipCyRxSR0A9IR50M4\&index=12, acesso em 10 de maio de 2020.

CENÁRIO|ISSN 2318-8561|Brasília|V.8, n. 14|6 - 16|Jun. 2020| DOI: $10.26512 /$ revistacenario.v8i14.31957
} 


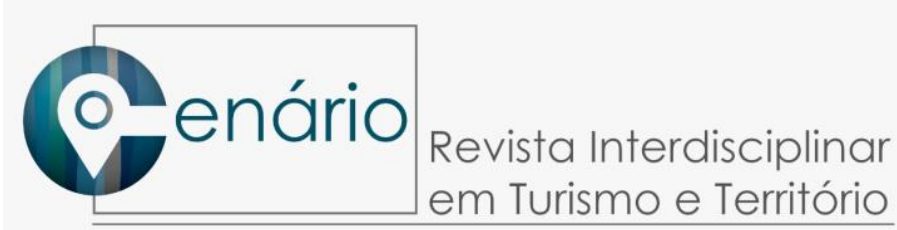

recursos disponíveis para realizá-la. O inviável é considerado impossível, e assim deve ser evitado. Planejamento é, assim, a construção racional de um futuro desejável e viável.

Vamos dar um pouco de praticidade a esse raciocínio. Imaginemos uma palestra proferida por um planejador a estudantes do ensino fundamental de uma escola privada. Após abrir a apresentação para perguntas, ouve dos garotos e garotas: 'podemos pensar em algum dia virmos de metrô para a escola na nossa cidade? O Brasil pode banir a maioria dos agrotóxicos em um futuro próximo? Podemos pensar em um serviço público de saúde universal e de qualidade? A escola poderia ser gratuita? Não, diria o planejador, isso é inviável neste momento. Por outro lado, podemos pensar em viagens de turismo para o espaço e a lua em um futuro próximo? Sim, diria o planejador, a tendência é essa mesmo, inclusive voos já houve. Transitando agora por uma filosofia mais sofisticada, o planejador representa a razão, detém a verdade e o governo do futuro. Manipula, assim, as emoções e paixões - os afetos - das crianças. Reforça o afeto 'medo' - de se transportar, de adoecer, de ingerir veneno, de ver espécies e biomas destruídos, de conseguir atendimento médico, de seus pais não poderem pagar a mensalidade da escola - e o afeto 'esperança' - de que nada disso aconteça. $O$ planejador governa o futuro das crianças, e as impede de pensar em qualquer possibilidade diferente do que está dado - porque é inviável, impossível - mas ainda cria uma expectativa de que elas um dia poderão viajar até a lua. Mas para tanto, terão que ganhar muito dinheiro. $O$ planejamento, da forma como está descrito, deturpa o método científico para manipular os afetos das pessoas e governar o seu tempo futuro, impedindo-as de sonhar um mundo melhor. Vivemos o capitalismo neoliberal ${ }^{5}$, em que ganhar dinheiro é a missão maior de uma pessoa, daí o valor representado nas palavras do nosso planejador imaginado. Percebam que, na realidade, é impossível separar razão e emoção no planejamento das sociedades, e que a transformação ou manutenção do status quo depende da forma como esses afetos são conduzidos ou manipulados. As transformações políticas não são o resultado das ideias, mas sim dos afetos: novos afetos produzem grandes ideias. Assim, não há nada mais racional do que os afetos ${ }^{6}$.

O filósofo Mangabeira Unger, um dos principais pensadores do desenvolvimento brasileiro e professor em Harvard, em entrevista recente ${ }^{7}$, narra a chegada de muitos economistas brasileiros, recém-formados, nas principais universidades americanas em busca de formular análises críticas aos modelos dominantes, desenvolver trabalhos contra-hegemônicos, mas não encontram orientadores. Seguindo o seu raciocínio, as instituições de ensino colocadas nas primeiras posições dos rankings internacionais obrigam os estudantes de pós-graduação a entrar na engrenagem do capitalismo neoliberal e ganhar dinheiro ${ }^{8}$. Assim, elas governam também o futuro das cabeças que poderiam pensar um Brasil que, como sonha o prof. Unger,

\footnotetext{
${ }^{5}$ Esta expressão é inevitável. Para entender o paradigma neoliberal, seguem algumas sugestões de leitura de David Harvey $(2005 ;$ 2008). Mas basicamente, é uma teoria e prática de política econômica que acredita que a melhor forma de se atingir o bem-estar humano é liberar as capacidades empreendedoras dos indivíduos, sob uma estrutura institucional capaz de assegurar os direitos de propriedade privada, desregulação dos mercados, e flexibilização dos direitos trabalhistas.

${ }^{6}$ Para quem desejar aprofundar a conversa, Vladimir Safatle (2016) constrói uma teoria social sobre o circuito dos afetos a partir do trabalho do filósofo Baruch Espinosa, e explica brevemente a sua teoria em https://www.youtube.com/watch?v=XBLEv5zjYc4\&t=3662s, acesso em 14 de maio de 2020.

${ }^{7}$ Uma entrevista que o Prof. Mangabeira Unger concedeu a Caetano Veloso, pela Mídia Ninja, que pode ser vista em https://www.youtube.com/watch?v=Mfv-4zQ9 Q0, acesso em 20 de abril de 2020.

${ }^{8}$ Para uma leitura instigante sobre o papel das instituições no governo do tempo das pessoas, ver Foucault (2012).

CENÁRIO|ISSN 2318-8561|Brasília|V.8, n. 14|6 - 16|Jun. 2020| DOI: $10.26512 /$ revistacenario.v8i14.31957
} 


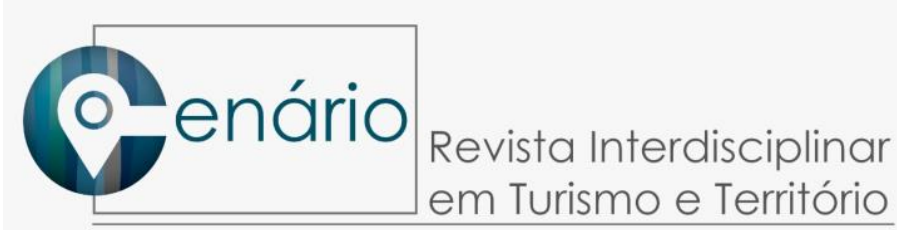

uniria pujança e ternura. Instituições e planejadores governam o futuro das pessoas de forma a manter tudo como está. Suprimem a curiosidade e enjaulam o talento das pessoas ao sufocá-las os afetos. Impedem, assim, que a razão possa transformar esses afetos passivos em ativos ${ }^{9}$, capazes de provocar transformações. Mas será que planejadores podem nos dar um futuro de libertação de nossos talentos, de autoconhecimento e solidariedade? Na realidade, a resposta para essa pergunta não é difícil, afinal de contas construir uma vida melhor para os cidadãos é o papel principal do planejador.

\section{O TEMPO DO TRABALHO E DO LAZER NO CAPITALISMO}

Em um artigo recente, o geógrafo David Harvey nos esclarece que uma sociedade rica é quando o seu povo possui tempo disponível para as artes, para a ciência, para o exercício das liberdades dos talentos ${ }^{10}$. Aprofundando a leitura de Marx, Harvey nos ensina que o capitalismo é contraditório, posto que, em sua evolução, ele nos liberta do trabalho realmente necessário, já que as necessidades básicas são supridas pelo emprego de tecnologias sofisticadas. Entretanto, ele promove o aumento da quantidade de trabalho supérfluo. Marx defende que a ação coletiva deve ser mobilizada para que as sociedades ganhem liberdade individual. Vejam que interessante, Marx fala de liberdade individual como o fim maior do processo de desenvolvimento das sociedades ${ }^{11}$. Mas para tanto, precisamos de ação coletiva para vencer o trabalho supérfluo que serve apenas ao enriquecimento das pequenas camadas privilegiadas das sociedades capitalistas, ao preço da ocupação da vida dos trabalhadores. No mundo de hoje, a força de trabalho foi socializada para se comportar como um conjunto de 'bons sujeitos neoliberais', continua Harvey. Pessoas que, alienadas do contexto em que vivem e sem capacidade de criticá-lo, costumam culpar algum deus ou a si mesmas se coisas dão errado em suas vidas. Mas agem assim muito mais por necessidade de sobrevivência do que por desejo pessoal livre. São vendedores que passam o dia nos empurrando produtos que não queremos, são estrategistas pragmáticos de publicidade infantil, lobistas de produtos e serviços que interferem e atrapalham a gestão pública e a inovação, investidores de dinheiro que apenas produzem mais dinheiro sem deixar legado algum, difusores de imagens mentirosas de lugares turísticos, etc. As ações de isolamento social causadas pela pandemia de COVID-19 estão nos mostrando que esses trabalhos são supérfluos e, assim, contribuem

\footnotetext{
${ }^{9}$ Para uma apresentação bem clara sobre afetos ativos e passivos, sugiro palestra do prof. André Martins https://www.youtube.com/watch?v= aEwGQgC2Pc\&t=2616s, acesso em 11 de maio de 2020.

10 https://www.jacobinmag.com/2020/04/david-harvey-coronavirus-pandemic-capital-economy, acesso em 30 de abril de 2020.

${ }^{11}$ Isso é muito interessante, porque Marx é normalmente relacionado a governos autoritários e limitadores da ação livre dos indivíduos. Aqui vale a pena sugerir a leitura do filósofo e economista liberal Amartya Sen (1999), que cita Marx vinte vezes em seu Development as Freedom, livro que reúne o resultado de trabalho que Ihe valeu o prêmio Nobel de Economia de 1998. Lendo Harvey e Sen, percebemos que, se os meios para se atingir as liberdades individuais substantivas são diferentes em suas abordagens, os fins em Marx e Sen são rigorosamente os mesmos.
} 


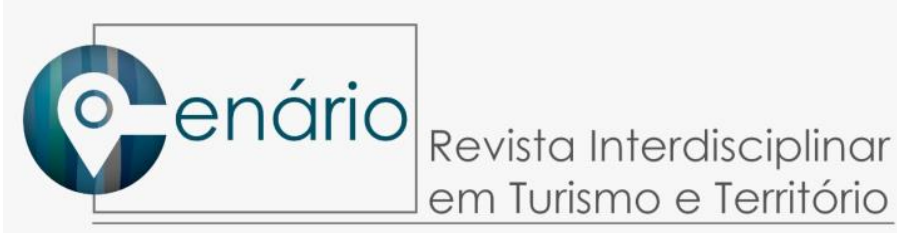

quase nada para a humanidade, para o caminho da civilização. Essas pessoas poderiam exercer seus talentos nas artes, ciências, esportes, fazendo invenções, se engajando em ações sociais, e contribuindo para que todos tivéssemos vidas melhores. Mas para que essa força de trabalho consiga se transmutar em ação coletiva para a libertação dos exercício dos talentos individuais, precisamos daquilo que o nosso patrono da educação Paulo Freire define como o processo de 'conscientização'. Conscientização é quando o sujeito age de acordo com o que acredita, sente e diz, em um exercício da liberdade de sonhar, de escolher e participar daquilo que for preciso para se atingir o que se deseja. Assim não é apenas uma teoria, mas uma prática de liberdade ${ }^{12}$. A conscientização dos trabalhadores os leva à emancipação e à capacidade de interferir no governo do desenvolvimento de suas sociedades, enfim, de seu tempo futuro.

O pesquisador social e planejador urbano Bent Flyvbjerg acompanhou o caso da revisão do planejamento urbano da cidade de Aalborg, na Dinamarca, nos anos $1980^{13}$. Tomou-lhe certo tempo entender por que algo sempre incomodava a condução dos debates para formular o plano urbanístico da cidade. Ele percebeu que havia um grupo de atores, muito mais forte do que os outros, que alterava de forma sorrateira o objetivo do plano, de beneficiar a cidade e as pessoas, para beneficiar seus próprios negócios. Ele descreve: 'Membros da comunidade local de comerciantes eram 'vendedores de poder', que se ocupavam de negociar acordos ilícitos com políticos e gestores públicos, sobre como bloquear a competição e o mercado livre, e criar privilégios especiais para eles mesmos'14. Hoje em dia no mundo ocidental e em boa parte do oriente, a voz mais forte do jogo democrático é a dos empresários. O discurso empresarial domina a constituição e interpretação das leis, justifica as ações públicas de desenvolvimento, governa o conceito de trabalho e liberdade, e resume o futuro das sociedades à simples expansão de riqueza e renda, que é o combustível das empresas. A alienação dos trabalhadores é fruto da crença nos valores espalhados pela sociedade de que os políticos são todos criminosos, a administração pública é ineficiente e corrupta, empresas públicas são ineficientes, qualquer imposto é malversado, movimentos sociais são terroristas, entre outros valores. Tudo aquilo que possibilitaria alguma redistribuição da riqueza e ampliação do tempo livre dos cidadãos comuns é sufocado. Os empresários e suas associações defendem a concorrência, mas apoiam a privatização de empresas monopolistas, ou oligopolistas. Fazem apologia à ostentação e constroem afetos de esperança entre os trabalhadores, de um dia terem aquilo tudo também - iates, piscinas, mansões - e, como vimos, governam o seu futuro. As pessoas são transformadas em empresas - que são vistas como a organização perfeita - e, caso não 'vençam na vida', a culpa é somente delas.

E vejam que são, em grande parte, os empresários - e vários de seus empregados 'bons sujeitos neoliberais' - a defender fortemente o negacionismo à

\footnotetext{
${ }^{12}$ Essa ideia está descrita no Pedagogia do Oprimido (Freire, 1970), mas para uma leitura com referência aos estudos de tempo livre, de ludicidade, sugiro o artigo de Leila Mirtes Pinto (2008).

${ }^{13} \mathrm{O}$ caso de Aalborg está no livro Rationality and Power: democracy in practice (Flyvbjerg, 1998).

${ }^{14}$ Tradução livre, de Flyvbjerg (2006, p. 228).
}

CENÁRIO|ISSN 2318-8561|Brasília|V.8, n. 14|6 - 16|Jun. 2020| DOI: $10.26512 /$ revistacenario.v8i14.31957 


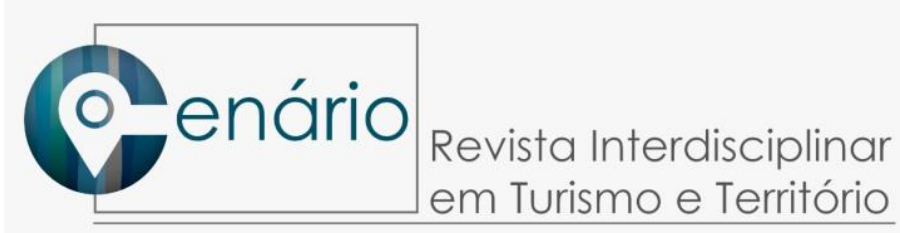

pandemia, ostentando os seus carros luxuosos nas carreatas criminosas, pedindo às massas de trabalhadores para retornarem ao trabalho. Um analista social poderia identificar aí o discurso conservador: o clamor por manter o mundo como estava antes da pandemia de COVID-19. Mas o conservadorismo não é cruel por si só. Torna-se cruel porque o mundo atual é cruel, e conservá-lo demonstra crueldade. Os conservadores legítimos percebem que algo está errado, e querem a mudança, mas que seja gradual ${ }^{15}$. Esses sujeitos negacionistas não são conservadores, e nem fascistas, porque lhes faltam o componente nacionalista. São apenas cidadãos deletérios, que justificam a necessidade das instituições democráticas, para mantê-los longe dos processos decisórios, mas de onde se encontram perigosamente próximos hoje no Brasil ${ }^{16}$.

Os empresários do turismo, tanto os negacionistas quanto os racionais, apoiam a agenda neoliberal do governo e especulam sobre quando tudo voltará ao normal. Preveem os cenários otimista e pessimista, sendo o otimista o retorno ao gigantesco fluxo turístico global, que alegam gerar riqueza e renda nas sociedades mais carentes, e o pessimista um retorno gradual, primeiro com viagens domésticas para, em alguns anos, se retomar o fluxo de antes da pandemia. Nada se fala do turismo em sua concepção mais plena, de fenômeno do tempo livre, do lazer, capaz de promover aprendizado e o autoconhecimento, aproximar culturas e gerar solidariedade, pertencimento e educação ambiental e patrimonial, afetos ativos e práticas humanas transformadoras entre os cidadãos: ócio em vez de negócio ${ }^{17}$. Não são valores importantes para o bom sujeito neoliberal.

O planejador ordinário de turismo também não consegue encontrar uma saída que não seja viável em relação à situação anterior à pandemia. Mantém o status quo, evita a transformação. Pois eu não me considero um planejador ordinário. Espero que nada volte ao normal, porque o normal estava horrível. Em vez de transcrever aqui páginas e mais páginas de estatísticas para demonstrar esse fato, apenas digo que a forma como somos governados hoje destrói as pessoas, pelas desigualdades sem precedentes, e o meio ambiente, o nosso habitat ${ }^{18}$. Observo ainda que vivemos hoje distantes dos amigos, da família, focados no trabalho de forma tão visceral, que sequer temos tempo para refletir sobre o que de fato queremos, os nossos desejos - e, conforme

\footnotetext{
${ }^{15}$ Para entender o conservadorismo, sugiro entrevista de João Pereira Coutinho https://www.youtube.com/watch?v=NCRKfS2en90, acesso em 10 de maio de 2020.

${ }^{16}$ O episódio mais evidente do negacionismo ao COVID-19 pelos empresários, e o completo domínio do Governo Federal pelo discurso empresarial, foi a caminhada do presidente, acompanhado de ministros e grandes empresários ao Supremo Tribunal Federal em 7 de maio de 2020, para defender o relaxamento das medidas de distanciamento social e, o pior, a recepção do grupo pelo presidente do Supremo Tribunal Federal:

https://g1.globo.com/politica/noticia/2020/05/07/bolsonaro-atravessa-praca-dos-tres-poderes-a-pe-e-vai-ao-stfacompanhado-de-ministros.ghtml, acesso em 14 de maio de 2020.

${ }^{17}$ Eu e três colegas desenvolvemos esse assunto em outro artigo. Ver Fazito et al (2017).

${ }^{18}$ Muito se fala sobre os resultados do paradigma hegemônico do capitalismo neoliberal, modernizador e globalizante. Na minha opinião, a leitura mais convincente sobre isso ainda é Escobar (1995), mas para uma abordagem mais acessível, recomendo o documentário sobre as reflexões do Milton Santos O Mundo Global Visto do Lado de Cá https://www.youtube.com/watch?v=-UUB5DW mnM\&t=81s, acesso em 10 de maio de 2020.
} 


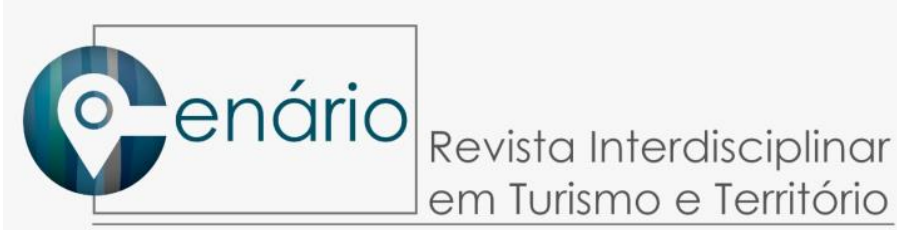

vimos, muito do trabalho excessivo com o que somos ocupados hoje é supérfluo e não nos realiza. E assim inundamos os consultórios de psicólogos e psiquiatras, terapias alternativas e os templos religiosos, buscando encontrar remédios fáceis para problemas complexos. 'A culpa é minha' ou 'Deus quis assim' são apenas mais formas de conviver com a manipulação dos nossos afetos por outrem. Um futuro melhor para todos não está em intervenções individuais, mas na ação coletiva. E que os psicólogos e psiquiatras nos ajudem a refletir com mais profundidade sobre a nossa condição, reencontrar o nosso desejo e a valorizar as nossas características pessoais: aquilo que nos diferencia dos outros; e que os templos religiosos nos ajudem a conviver com o desconhecido, com aquilo que não conseguimos explicar, e nos tragam paz interior, enfim, que nos ajudem a buscar a melhor convivência com a nossa espiritualidade.

\section{O EFEITO 'VONTADE' E O PAPEL DOS PLANEJADORES DE TURISMO NA CONSTRUÇÃO DE UM FUTURO MELHOR}

Há algumas décadas, o medo de uma iminente pandemia mortal já vinha se mostrando continuamente presente, fazendo com que a frase 'não se questiona se haverá uma pandemia, mas quando ela ocorrerá' tenha aparecido em filmes documentários, discursos de formatura na área de saúde, e até mesmo em discurso do ex-presidente dos Estados Unidos Barack Obama, este último ocorrido em $2014^{19}$. Fundado na atração irresistível que sentimos pela nossa própria destruição, muito se investiu no medo para que lucros exorbitantes fossem auferidos pela indústria cinematográfica (medo de doenças, monstros, medos ficcionais), bélica (medo da nação inimiga), automobilística, imobiliária e de segurança privada (medo das ruas, do espaço público), além de facilitar a vida de governos inescrupulosos por todo o mundo (medo de ficar sem salário, sem comida ou sem liberdade). Entretanto, a maioria dos países - e a pandemia de COVID-19 deixou isso claro - não fez os investimentos necessários para minimizar os riscos e responder da forma mais rápida possível a tal pandemia iminente. Muito pelo contrário, países que figuram nos topos dos rankings dos índices de desenvolvimento diminuíram tais investimentos, seguindo a agenda neoliberal promovida pelos 'maiores estrategistas do globo', desde suas universidades de ponta, agências de desenvolvimento, think tanks de geopolítica global. Percebe-se aí que não só a análise fria de dados e as evidências racionais interferem nas decisões de planejamento para o governo do tempo futuro das pessoas, mas principalmente as vontades e desejos das classes abastadas, que refletem nos prognósticos desenvolvidos pelos planejadores. Assim, não constroem uma situação futura desejada para as sociedades, mas inventam o futuro que querem, aquele que as beneficia.

Há, assim, duas possibilidades sobre o futuro do turismo pós-pandemia: em uma primeira, tudo volta ao normal (viagens domésticas se normalizam no Brasil até 2022, e viagens internacionais até $2025^{20}$ ), o que representa ao mesmo tempo o viável, o possível, e o desejo do planejador neoliberal; a segunda possibilidade sugere que haverá mudanças radicais. Prof. Sarah Dolnicar, em evento recente sobre o futuro da pesquisa em turismo em um mundo póspandemia, sugere que a primeira hipótese se dará caso se descubra, por exemplo, uma vacina

\footnotetext{
${ }_{19}$ Pode ser visto em https://www.youtube.com/watch?v=pBVAnaHxHbM, com acesso em 27 de abril de 2014.

${ }^{20} \mathrm{https://www.ft.com/content/c3d4a61f-f8da-4794-932e-92dac87017e7,} \mathrm{acesso} \mathrm{em} 13$ de maio de 2020.

CENÁRIO|ISSN 2318-8561|Brasília|V.8, n. 14|6 - 16|Jun. 2020| DOI: $10.26512 /$ revistacenario.v8i14.31957
} 


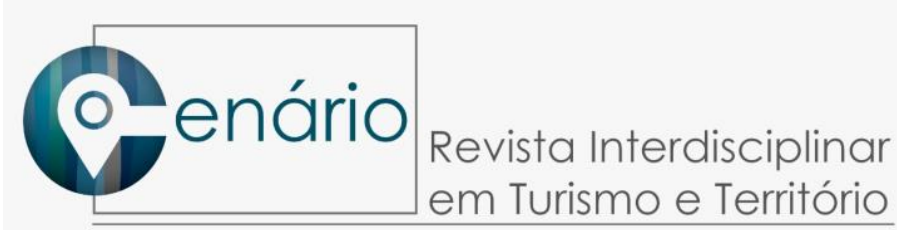

contra o COVID-19 em breve, e coloca a segunda possibilidade como se nunca encontrarmos a cura para a doença, o que impactaria o número de viagens e os seus procedimentos, como o uso de tecnologias para desinfetar as pessoas, as coisas e os ambientes. Eu acredito que esses meses de isolamento, distanciamento e quarentenas já nos deu tempo, experiência e elementos necessários para nos autorizarmos a pensar sobre o futuro.

Vamos refletir sobre a primeira possibilidade, de que o turismo voltará ao que era antes da pandemia. A primeira consideração é que, nessa hipótese, precisamos demonstrar que o que define 'positivo' e 'negativo' são as variações de renda e riqueza proporcionadas pelo turismo, ou seja, para os planejadores que desejam ver tudo voltar ao normal, turismo e a indústria que o apoia são rigorosamente a mesma coisa. Senão vejamos. Após entrarem de cabeça na onda neoliberal e defenderem o estado mínimo, a desregulamentação dos mercados, as fusões de grandes companhias transnacionais e a flexibilização das leis trabalhistas nas décadas recentes, os representantes dos setores econômicos que apoiam o turismo agora pedem investimento governamental para salvar o turismo. Por exemplo, a Organização Mundial do Turismo agora pressiona os governos a investir na indústria do turismo, para recuperá-la ${ }^{21}$. Nesse artigo, a organização defende que 'governos têm a oportunidade de reconhecer a habilidade única do turismo de não somente gerar emprego, mas também contribuir para a igualdade e inclusão'. Ora, desde do famoso artigo de Stephen G. Britton, The political economy of tourism in the third world, que os estudiosos do Turismo sabem que essa ideia de que o turismo, da forma como é planejado e implementado hoje, gera distribuição de renda, igualdade e desenvolvimento econômico é uma falácia ${ }^{22}$. A maior parte das despesas dos turistas fica com as grandes empresas aéreas, grandes bandeiras internacionais de hotéis, grandes operadoras, sobrando pouco para os trabalhadores, residentes e administrações locais nos destinos turísticos. Quanto menos o Estado interfere nas relações comerciais entre as empresas e seus empregados e entre elas e o território que ocupam, menos recursos ficam nesses territórios. Entretanto os residentes dos territórios turísticos têm que conviver com a inflação nos preços dos produtos, de aluguéis e valor de imóveis, com a pressão na infraestrutura local e despesas com sua manutenção, impactos no ambiente natural e em seu patrimônio material e imaterial, e com o domínio do discurso empresarial nas decisões de desenvolvimento público ${ }^{23}$. Assim como na OMT, as instâncias públicas de gestão do turismo mundo afora são ocupadas por representantes do mercado e empresários da indústria que apoia o turismo e, assim, são dominadas pelo discurso dos negócios.

Podemos inserir essa realidade descrita acima no conceito de 'globalização como perversidade', conforme definido pelo geógrafo Milton Santos, sendo que somos convencidos de que essa realidade é boa a partir de uma enganadora 'globalização como fábula', mas que ambas devem ser desconstruídas pelos movimentos sociais para dar origem a uma vida melhor, 'uma

\footnotetext{
${ }^{21}$ https://www.unwto.org/news/firm-action-by-governments-to-support-tourism-recovery-covid-19, acesso em 13 de maio de 2020.

${ }^{22}$ Britton (1982) demonstrou que o contato com os países ricos emissores de turistas não trouxe - e não traria desenvolvimento econômico aos países pobres. Mas a ideia do turismo contemporâneo ser gerador de desigualdades tem já uma profícua e ampla literatura, bem como suas possibilidades, ainda utópicas, de promover o oposto. Para começar, sugiro a leitura de Tourism and Inequality: problems and prospects (Cole \& Morgan, 2010).

${ }^{23}$ Há extensa literatura sobre os impactos negativos do turismo contemporâneo, tanto nas metrópoles globais quanto nas comunidades mais frágeis do globo. Mas faço aqui a sugestão de dois filmes: Gringo Trails https://www.youtube.com/watch?v=uKuwGheoBew, e Terramotourism https://www.youtube.com/watch?v=i5xAh-V9DpQ, acesso em 14 de maio de 2020.

CENÁRIO|ISSN 2318-8561|Brasília|V.8, n. 14|6 - 16|Jun. 2020| DOI: 10.26512/revistacenario.v8i14.31957
} 


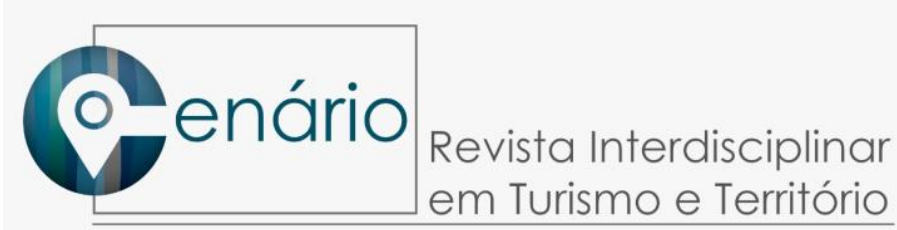

outra globalização'24. Uma boa contribuição a essa 'outra globalização' seria dada a partir da ocupação da internet como espaço público, em que as economias compartilhadas substituiriam o domínio dos grandes aglomerados empresariais. Assim, trocaríamos transporte e hospedagem, em um fenômeno de solidariedade poucas vezes visto na história da humanidade, mas agora de forma global. Assim, reinventaríamos a economia de forma a torná-la mais eficiente, como descreveu o filósofo Ricardo Abramovay em Muito Além da Economia Verde. Poucos anos depois, o próprio filósofo criticaria essa ideia, posto que a internet teve o seu espaço ocupado por novas empresas globais a definir a forma como esse compartilhamento aconteceria, como a Uber, no caso dos transporte, ou o Airbnb, quanto à hospedagem, entre muitas outras. Para ele, o nosso papel agora é reocupar a internet enquanto espaço público ${ }^{25}$. Essa ideia nos remete a um mundo diferente do que esperam os planejadores neoliberais, e é sobre essa segunda possibilidade que me atenho agora.

Sobre isso, cento e setenta professores neerlandeses lançaram um manifesto ${ }^{26}$, em que elencam cinco medidas que precisam ser tomadas para que o país retome um caminho mais civilizatório, que eles consideram antineoliberal. Essas medidas versam sobre escolher as indústrias que devem/podem crescer (educação, energias limpas, saúde, setores públicos críticos) e as que devem decrescer radicalmente (petróleo, gás, mineração, publicidade), estabelecer a renda básica universal - que liberaria os trabalhadores dos fazeres supérfluos -, impostos sobre fortunas e redução da jornada de trabalho, implementar uma produção agrícola justa e sustentável, cancelar as dívidas de países pobres e pequenos empresários e trabalhadores e, por fim, uma medida que interessa mais para o nosso tema: reduzir o consumo e as viagens, com uma mudança drástica de viagens luxuosas e inúteis para consumo e viagens básicas, necessárias, sustentáveis e satisfatórias. Essa última medida vai de encontro ao que desejam os empresários de acomodação e transporte, que apoiam o turismo, e que o querem de forma massiva e descontrolada novamente. E que desejam o primeiro cenário, de que tudo volte ao normal.

De forma análoga à educação e à saúde, e às indústrias que as apoiam, o turismo também é bem mais importante para a humanidade do que a indústria que o apoia. Se os médicos brasileiros tivessem tido a oportunidade de visitar as comunidades remotas que, a partir de 2013, passaram a ter acesso a um médico para acompanhar a saúde de suas famílias com o Programa Mais Médicos, talvez tivessem tido uma posição distinta sobre expulsar sob vaias e xingamentos os médicos que vieram do exterior para o serviço ${ }^{27}$. Claro que esses médicos brasileiros usariam a indústria do transporte, da acomodação, de alimentos, mas a importância do turismo seria tê-los transformado como cidadãos, como seres humanos. O mesmo poderia ser dito de um banqueiro a visitar um assentamento de produção agroecológica de membros do Movimento Sem Terra, ou de um ativista da causa ambiental a visitar um produtor rural que passa

\footnotetext{
${ }^{24}$ Talvez o livro mais acessível de Milton Santos seja o ‘Por Uma Outra Globalização: do pensamento único à consciência universal' (2011).

25 O livro Muito Além da Economia Verde foi lançado em 2012 (Abramovay, 2012), e a crítica se deu no Encontro da Associação de Pós-Graduação e Pesquisa em Ambiente e Sociedade (ENANPPAS), em Natal, 2017.

${ }^{26}$ https://www.elclarin.cl/2020/04/23/holandeses-avanzan-en-el-escenario-pospandemia-y-proponen-un-modeloeconomico-basado-en-el-

decrecimiento/?fbclid=IwARONhdleAC8maumDWY0ZIOh02kT9SZR30SoVMcuKnmbLEvvZDFo9V39FFB8, acesso em 14 de maio de 2020.

${ }^{27}$ https://www1.folha.uol.com.br/cotidiano/2018/11/cubano-recebido-com-vaias-e-surpreendido-com-fim-deparceria-nao-sei-como-fica.shtml, acesso em 5 de junho de 2020.
}

CENÁRIO|ISSN 2318-8561|Brasília|V.8, n. 14|6 - 16|Jun. 2020| DOI: $10.26512 /$ revistacenario.v8i14.31957 


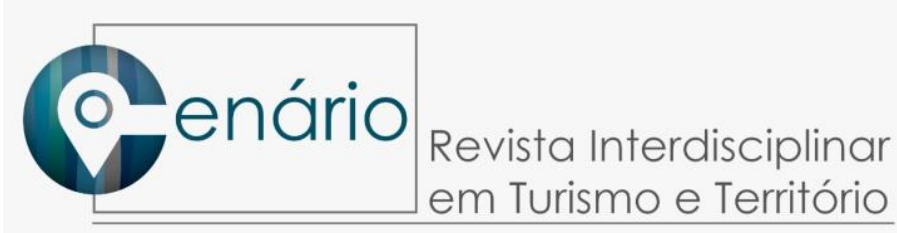

por dificuldades para obter licenças para produzir, ou ainda excursões de colégio para promover o encontro das crianças com o seu patrimônio, seja natural, construído ou simbólico. O turismo promove o encontro com o desconhecido e torna-o conhecido, promovendo entendimento entre grupos, povos e nações, gera prazer, confiança e comunhão ${ }^{28}$. Movimentar a indústria é apenas a consequência de um processo de construção de criticidade, pertencimento e encontro com afetos de cidadania. São programas como esses que eu gostaria de ver lançados pelo governo, e que a indústria corresse para apoiá-los.

A visão do retorno de minha filha às aulas na escolinha de Berlim foi assustadora. As crianças permanecendo a um metro e meio das outras, sem poderem se abraçar, se tocar, se aproximar, gerando formas geográficas perfeitas de pessoinhas com máscaras, olhos tristes e disciplina militar. Professores a ditar-lhes as regras. Lembrou-me ficções pós-apocalípticas. Visões como essa nos lembram que a pandemia de COVID-19 é uma oportunidade para que as elites globais ampliem o domínio da humanidade pelo medo, e que essa é a tendência, diria o planejador. Mas pode ser o oposto. Deve ser o oposto! Tenhamos as crianças como o centro do nosso conceito de desenvolvimento, de planejamento e de futuro. Elas não são gerações futuras, mas atuais. Queremos que nossos filhos cresçam para se tornarem a classe trabalhadora de hoje em dia? Trabalhando em ofícios supérfluos para realizar o sonho alheio? ${ }^{29}$ Não! Então, planejadores e turismólogos, ao trabalho!

\section{Referências}

Abramovay, R. (2012). Muito Além da Economia Verde. Editora Planeta Sustentável.

Britton, S. (1982). The Political Economy of Tourism in the Third World. Annals of Tourism Research, 9(3), 331-358.

Cole, S., \& Morgan, N. (2010). Tourism and Inequality: Problems and Prospects. CABI.

Cowen, M., \& Shenton, R. (2005). Doctrines of Development. Routledge.

Dardot, P., \& Laval, C. (2017). Comum: Ensaio sobre a revolução no século XXI. Boitempo.

Escobar, A. (1995). Encountering Development: The making and unmaking of the third world. Princeton University Press.

Fazito, M., Rodrigues, B., Nascimento, E., \& Pena, L. (2017). O Papel do Turismo no Desenvolvimento Humano. Papers Do NAEA, 372, 1-21.

Flyvbjerg, B. (1998). Rationality and power: Democracy in practice. University of Chicago Press.

\footnotetext{
${ }^{28}$ Muitos autores consideram que a saída desse modelo perverso que nos governa se dará pela comunhão, pelo senso de comunidade global. Sobre isso, há um excelente livro chamado Comum: ensaio sobre a revolução no século XXI (Dardot \& Laval, 2017).

${ }^{29}$ Leituras interessantes sobre isso: https://www.rt.com/op-ed/488686-lockdown-coronavirus-normal-uk/, https://outraspalavras.net/trabalhoeprecariado/a-estranha-sociedade-dos-empregos-de-merda/, acesso em 5 de junho de 2020.
}

CENÁRIO|ISSN 2318-8561|Brasília|V.8, n. 14|6 - 16|Jun. 2020| DOI: $10.26512 /$ revistacenario.v8i14.31957 
Flyvbjerg, B. (2006). Five Misunderstandings about Case-Study Research. Qualitative Inquiry, 12(2), 219-245.

Foucault, M. (2012). A Arqueologia do Saber (Edição: 8). Forense Universitária.

Freire, P. (1970). Pedagogia do Oprimido. Paz e Terra.

Harvey, D. (2005). A Brief History of Neoliberalism (New Ed). Oxford University Press.

Harvey, David. (2008). Neoliberalismo (O)—História e implicações. Loyola.

Pinto, L. (2008). Lazer e Educação: Os desafios da atualidade. In N. Marcellino (Ed.), Lazer e Sociedade: Multiplas relações (pp. 11-26). Alinea.

Safatle, V. (2016). O Circuito dos Afetos: Corpos políticos, desamparo e o fim do indivíduo. Autêntica.

Santos, M. (2011). Por Uma Outra Globalização: Do pensamento único à consciência universal. Record.

Sen, A. (1999). Development as Freedom. Oxford University Press. 